\title{
Frailty as a Predictor of Alzheimer's Disease, Vascular Dementia, and All Dementia among Community-Dwelling Older People: A Systematic Review and Meta-analysis
}

\begin{abstract}
Objective: To perform a systematic search of the literature for currently available evidence on frailty as a predictor of dementia and to conduct a meta-analysis to synthesize the pooled risk estimates among community-dwelling older people.
\end{abstract}

Design: A systematic review and meta-analysis.

Data Sources: Embase, MEDLINE, CINAHL Plus, PsycINFO, and the Cochrane Library from 2000 to January 2016, and reference lists of relevant articles.

Eligibility Criteria: Any studies that prospectively examined the incident risks of dementia with frailty among community-dwelling older people without language restriction.

Results: Of 2,565 studies identified through the systematic review, seven studies were included in this review. Of these, four studies reported hazard ratios (HR) of incident dementia for physical frailty defined by Cardiovascular Health Study criteria and were included in a meta-analysis. Frailty was a significant predictor of incident Alzheimer's disease (four studies: pooled $\mathrm{HR}=1.28,95 \%$ confidence interval $(95 \% \mathrm{CI})=1.00-1.63$, $\mathrm{p}=0.05$ ), vascular dementia (two studies: pooled $\mathrm{HR}=2.70,95 \% \mathrm{CI}=1.40-5.23, \mathrm{p}=0.003$ ), and all dementia (three studies: pooled $\mathrm{HR}=1.33,95 \% \mathrm{CI}=1.07-1.67, \mathrm{p}=0.01$ ). Heterogeneity across the studies was low to modest $\left(\mathrm{I}^{2}=0-51 \%\right)$. A random-effects meta-regression analysis showed that the female proportion of the cohort primarily mediated the association of frailty with Alzheimer's disease (female proportion coefficient $=0.04,95 \% \mathrm{CI}=0.01-0.08, \mathrm{p}=0.01$ ).

Conclusion: This systematic review and meta-analysis suggests that frailty was a significant predictor of Alzheimer's disease, vascular dementia, and all dementia among communitydwelling older people. Frail women may have a higher risk of incident Alzheimer's disease than frail men.

Keywords: Frailty; Dementia; Alzheimer's disease; Community-dwelling older people. 


\section{INTRODUCTION}

Dementia is a neurocognitive disorder characterized by deteriorations in memory, language, and other cognitive functions, and influences an individual's ability to perform every day activities. ${ }^{1}$ Dementia typically is a major cause of disability and dependence in older adults ${ }^{2}$ and nearly 35.6 million people live with dementia worldwide. ${ }^{3}$ The prevalence of dementia in people age 60 years or older is $5-7 \%,{ }^{2}$ which increases with age, and approximately one-third of people have dementia when they die. ${ }^{4}$ Given that currently available pharmacological interventions can neither cure nor reverse dementia (but only offer limited symptom modification), it is a pressing issue to identify potentially modifiable risk factors for dementia. ${ }^{5,6}$

One of the possible candidates is frailty. Frailty is a geriatric syndrome with the main features of age-related decline in multi-system physiological reserve and reduction in the ability to tolerate external and internal stressors, leading to vulnerability to adverse health outcomes. ${ }^{7} \mathrm{~A}$ physical phonotype of frailty ${ }^{8}$ has been characterized as having low energy, low physical activity, slow gait speed, weakness, and weight loss. The adverse outcomes associated with frailty include disability, falls, hospitalization, institutionalization, fracture, poor quality of life, and mortality. ${ }^{7-12}$ The prevalence rates vary, ranging from $4.0 \%$ to $59.1 \%$, and an overall weighted prevalence rate is $10.7 \%$ in community-dwelling older adults aged 65 or more. ${ }^{13}$ Approximately $25 \%$ of people aged 85 or more ${ }^{13}$ and more than $50 \%$ of institutionalized people $^{14}$ are frail.

Although frailty has been studied for various adverse outcomes, ${ }^{7}$ a limited number of studies have investigated prospective associations of frailty with dementia and reported inconsistent results. ${ }^{15-18}$ Among five studies that examined association between baseline frailty and subsequent Alzheimer's disease, only one study ${ }^{16}$ showed a significant association while the rest of the studies ${ }^{15,17-19}$ showed negative results. Furthermore, two studies reported that individuals with frailty at baseline had significantly higher risk for all type dementia compared with non-frail counterparts, ${ }^{17,20}$ but two other studies did not. ${ }^{15,18}$

Recently two systematic review articles summarized associations of frailty with dementia. ${ }^{21,22}$ The first was a systematic review of the literature up to $2010^{21}$ and identified only one prospective study of associations between frailty and Alzheimer's disease. ${ }^{16}$ The second review identified three previous studies that examined baseline frailty and subsequent Alzheimer's disease ${ }^{16,17,19}$ and conducted a meta-analysis. However, this meta-analysis was statistically compromised by combining different types of effect measures and using different frailty criteria. In addition, this review paper did not include important studies. ${ }^{15,18}$ Therefore the associations of frailty with Alzheimer's disease and other dementias are still to be elucidated and reliable pooled evidence is needed. The current systematic review and metaanalysis had two objectives: to perform a comprehensive systematic search of the literature on the associations of frailty with dementia among community-dwelling older people, and to conduct a meta-analysis to synthesize the pooled risk estimates.

\section{METHOD}

\section{Data Sources and Search Strategy}

A systematic literature search was conducted in January 2016 based on a protocol developed in accordance with Preferred Reporting Items for Systematic Review and Meta-Analyses (PRISMA) $^{23}$ and Meta-analysis of Observational Studies in Epidemiology (MOOSE) ${ }^{24}$ statements. Five electronic databases (Embase, MEDLINE, CINAHL Plus, PsycINFO, and the Cochrane Library) were searched for studies published in 2000 or later without language 
restriction and with an explosion function if available. The publication period was decided based on the fact the most widely used definition of frailty, Fried phenotype, was published in $2001 .^{8}$

The search terms used included as follows:

(Dementia (Medical Subject Heading (MeSH))) OR (Alzheimer('s) Disease (MeSH)) OR (Dementia with Lewy Bodies (MeSH)) OR (Lewy Body Disease (MeSH)) OR (Multiinfarct Dementia (MeSH)) OR (Dementia, Multi-Infarct (MeSH)) OR (Vascular Dementia (MeSH)) OR (Dementia, Vascular (MeSH)) OR (Frontotemporal Dementia (MeSH)) OR (Frontal Variant Frontotemporal Dementia (MeSH)) OR (Dementia, Senile (MeSH)) OR (Senile Dementia (MeSH)) OR (Presenile Dementia (MeSH)) OR (Dementia, Presenile (MeSH)) OR (Delirium, Dementia, Amnestic, Cognitive Disorders (MeSH)) OR (dementia) OR (alzheimer)

AND

(Frail Elderly (MeSH)) OR (Frailty Syndrome (MeSH)) OR (Frailty).

Bibliographies of included and relevant studies and review articles were manually searched. Studies known to the authors were also reviewed for references.

\section{Study Selection}

All prospective studies that examined baseline frailty status according to criteria which have been specifically designed for frailty and validated in population-based studies and subsequent incident dementia if any kind among community-dwelling older adults aged 65 or older were potentially eligible. Frailty status included, where applicable, both frail and prefrail groups. For example in studies using the Fried phenotype to determine frailty status, those scoring 0 are robust, 1-2 are prefrail and 3 or more are frail. The baseline cohorts should be dementia-free and dementia should be diagnosed based on established diagnostic criteria such as Diagnostic and Statistical Manual of Mental Disorders (DSM) or National Institute of Neurological and Communicative Disorders and Stroke and Alzheimer's Disease and Related Disorders Association criteria (NINCDS-ADRDA). Mild cognitive impairment (MCI) or cognitive changes as an outcome were not considered in this study. Studies were excluded if they were review papers, randomized controlled trials, conference abstracts, editorials, or comments. When the same cohort was used by multiple studies, the one with a longer follow-up period or a larger sample size was chosen for a meta-analysis. An adjusted effect measure was preferred when a study reported adjusted and unadjusted ones. Two researchers (GK and YT) independently screened title, abstract, and full-text of all studies identified by the literature search for eligibility. Disagreements were resolved by discussion.

\section{Data Extraction}

The two researchers (GK and YT) independently extracted characteristics of the included studies, including first author, study cohort name, publication year, location, sample size (analysis of interest or the entire cohort), proportion of female participants, age (mean and range or age criterion for inclusion), frailty criteria, dementia outcome, dementia criteria, effect measure, and follow-up period, as well as study findings which included risk estimates, such as OR or HR, along with $95 \%$ confidence intervals and covariates used for adjustment in the final models.

\section{Methodological Quality Assessment}

Studies presumed as eligible through title, abstract, and full-text screening were examined for methodological quality using the 9-scale Newcastle-Ottawa scale for cohort studies. ${ }^{25}$ A study was considered to have adequate quality of methodology when it met five or more out of nine 
criteria.

\section{Statistical Analysis}

All analyses were performed using Review Manager 5 (version 5.2, The Cochrane

Collaboration, Copenhagen, Denmark), Comprehensive Meta-Analysis (version 3.3, Biostat, New Jersey, USA), and StatsDirect (version 2.8, StatsDirect, Cheshire, UK), and the level of significance was set at $p \leq 0.05$.

Hazard ratio (HR) or odds ratio (OR) with $95 \%$ confidence intervals of risks of incident dementia for frailty and prefrailty compared with non-frailty/robustness were extracted from the included studies according to types of dementia (Alzheimer's disease, vascular dementia, or all dementia). The presence of heterogeneity across the studies was assessed using the chi square test and considered as present if the $p$ value was less than 0.05 . The degree of the heterogeneity was assessed by using $I^{2}$ statistic and $I^{2}$ value of $25 \%, 50 \%$, and $75 \%$ were considered as low, moderate, and high degrees of heterogeneity, respectively. ${ }^{26} \mathrm{~A}$ fixedeffects meta-analysis was conducted to calculate a pooled risk estimate for frail and prefrail groups separately using the generic inverse variance method. If heterogeneity was detected across the studies, a random-effects meta-analysis was used instead. Publication bias was assessed by visually examining a funnel plot and performing Begg-Mazumdar's ${ }^{27}$ and Egger's ${ }^{28}$ tests.

The pooled risk of incident dementia by frailty was further examined using a random-effects meta-regression analysis to explore study characteristics, including sample size, female proportion of the cohort, mean age, follow-up period, and methodological quality score, for a possible modulator effect on the associations between frailty status and subsequent risk of incident dementia.

\section{RESULTS}

\section{Selection Processes}

A systematic search of the literature using five electronic databases identified 2,564 studies, and one study ${ }^{20}$ was found via searching bibliographies of the relevant articles. Among the 2,565 studies, 832 duplicate studies and 1,722 studies that were considered irrelevant to this review during title and abstract screening were excluded, leaving 11 studies for full-text review. Four studies were further excluded because two studies did not use dementia as an outcome and another two were editorials or comments. The remaining seven studies ${ }^{15-20,29}$ were examined for methodological quality and considered to have adequate quality. Among these, four studies ${ }^{15-18}$ reporting HR of baseline frailty for risk of incident dementia were included in the meta-analysis. Three studies ${ }^{19,20,29}$ were not used in the meta-analysis because two studies ${ }^{19,20}$ did not use frailty categorization but expressed frailty status as a continuous score, the Frailty Index (FI), and, of the two studies using the sameThree City Study cohort, ${ }^{15,29}$ the one with the larger number of participants and longer follow-up period ${ }^{15}$ was included in the meta-analysis. A PRISMA flow chart of the literature search is shown in Figure 1.

\section{Study Characteristics}

Study characteristics and methodological quality score of the seven studies included in this study are summarized in Table 1. For study location, two studies ${ }^{16,17}$ were from the US using the Adult Changes in Thought ${ }^{17}$ and the Rush Memory and Aging Project ${ }^{16}$ cohorts. Two papers ${ }^{19,20}$ used the Canadian Study of Health and Aging cohort, and another two papers ${ }^{15,29}$ used the Three-City Study in France. One Paper was from Italy using the Italian Longitudinal 
Study of Aging. ${ }^{18}$ Sample size ranged from $823^{16}$ to $5480^{15}$. One study ${ }^{20}$ reported the findings in men and women separately, while the rest used mixed cohorts. Mean age ranged from $73.1^{18}$ to $80.4^{16}$, but two studies ${ }^{19,20}$ did not report it. To define frailty, five studies ${ }^{15-18,29}$ used modified Cardiovascular Health Study (CHS) criteria and two studies ${ }^{19,20}$ used FI. Various diagnostic criteria were used for dementia diagnoses, including NINCDS-ADRDA ${ }^{16-19}$, National Institute of Neurological and Communicative Disorders and Stroke-Association Internationale pour la Recherche en 1'Enseignement en Neurosciences (NINCDS-AIREN) ${ }^{15}$, International Statistical Classification of Diseases and Related Health Problems 10th version $(\mathrm{ICD}-10)^{18}$, or DSM ${ }^{15,17-20,29}$. For dementia outcomes, five different outcomes were used: Alzheimer's disease $(n=5)$, vascular dementia $(n=2)$, non-Alzheimer's disease dementia $(\mathrm{n}=1)$, other dementia than Alzheimer's disease and vascular dementia $(\mathrm{n}=1)$, and all dementia $(n=6)$. Follow-up period ranged from $3^{16}$ to $10^{19,20}$ years. Five studies presented adjusted HR of incident dementia for frailty compared with non-frailty or robustness, and two studies ${ }^{19,20}$ presented adjusted OR based on frailty status measured by the FI. Regarding assessment of methodological quality, the five studies using CHS criteria scored high at 8/9 while the two studies using FI scored $7 / 9^{19}$ and $6 / 9^{20}$.

\section{Frailty as a Predictor of Incident Dementia \\ Meta-analysis}

HRs from the four studies using CHS criteria to define frailty ${ }^{15-18}$ were combined to calculate pooled estimates according to types of dementia (Alzheimer's disease, vascular dementia, and all dementia). Synthesized results showed that baseline frailty was significantly associated with increased risks of developing Alzheimer's disease ( 4 studies $^{15-18}$ : pooled HR=1.28, $95 \% \mathrm{CI}=1.00-1.63, \mathrm{p}=0.05)$, vascular dementia ( 2 studies $^{15,18}$ : pooled $\mathrm{HR}=2.70$, $95 \% \mathrm{CI}=1.40-5.23, \mathrm{p}=0.003$ ), and all dementia ( 3 studies $^{15,17,18}$ : pooled $\mathrm{HR}=1.33$, $95 \% \mathrm{CI}=1.07-1.67, \mathrm{p}=0.01$ ). (Figure 2) Heterogeneity was low to moderate in these three study groups $\left(\mathrm{I}^{2}=51 \%, \mathrm{p}=0.10 ; \mathrm{I}^{2}=0 \%, \mathrm{p}=0.98 ; \mathrm{I}^{2}=13 \%, \mathrm{p}=0.32\right.$, respectively). Baseline prefrailty showed no significant associations with incident Alzheimer's disease and all dementia as compared with robust individuals $\left(2\right.$ studies $^{15,17}$ : pooled $\mathrm{HR}=0.91,95 \% \mathrm{CI}=0.78$ $1.08, \mathrm{p}=0.28,2$ studies $^{15,17}$ : pooled $\mathrm{HR}=0.98,95 \% \mathrm{CI}=0.85-1.14, \mathrm{p}=0.84$, respectively). Only one study ${ }^{15}$ examined prefrailty in relation to vascular dementia and showed nonsignificant result (adjusted $\mathrm{HR}=1.74,95 \% \mathrm{CI}=0.98-3.40, \mathrm{p}=0.10$ ). Although ORs were provided by two studies ${ }^{19,20}$ from the Canadian Study of Health and Aging using the FI, we did not conduct a meta-analysis as these studies used the same cohort.

\section{Meta-regression Analysis}

A random-effects meta-regression analysis was conducted among four studies with Alzheimer's disease outcomes to investigate potential modulator effects of study characteristics. The other dementia outcome groups included too few studies $(n \leq 3)$ for this analysis. Among the sample size, the female proportion of the cohorts, mean age, and followup period, only the female proportion was found to be a significant modulator of the association between frailty and incident Alzheimer's disease (female proportion coefficient $=0.04,95 \% \mathrm{CI}=0.01-0.08, \mathrm{p}=0.01$; intercept coefficient $=-2.49,95 \% \mathrm{CI}=-4.66$ to $0.35, \mathrm{p}=0.03)$. It was suggested that the female proportion explained all the between-study variance $\left(\mathrm{R}^{2}\right.$ analog=1.00). A bubble plot with a fitted meta-regression line clearly showed the linear association between the female proportion of the cohorts and risks of incident Alzheimer's disease according to frailty. (Figure 3).

\section{Publication Bias Assessment}

Publication bias was assessed among the four studies reporting risk of incident Alzheimer's 
disease. No evidence of publication bias was detected by using Begg-Mazumdar's ( $p=0.75$ ) and Egger's ( $p=0.76)$ tests. The studies on vascular dementia or all dementia and the funnel plots could not be examined for publication bias due to the small numbers of the studies.

\section{DISCUSSION}

This systematic review and meta-analysis demonstrated that baseline physical frailty is a statistically significant predictor of Alzheimer's disease, vascular dementia, and all dementia among community-dwelling older people. Among four previous studies examining the associations of frailty with incident Alzheimer's disease, we confirmed moderate heterogeneity and no evidence of publication bias. A random-effects meta-regression analysis showed that women with frailty had a higher risk of Alzheimer's disease than men with frailty.

We observed that pooled risk estimates of incident Alzheimer's disease (pooled HR=1.28) and all dementia (pooled HR=1.33) were relatively smaller than that of vascular dementia (pooled HR=2.70). There has recently been a growing interest in complex pathophysiological processes of Alzheimer's disease, which were shown to precede early clinical symptoms by decades. ${ }^{1,30}$ Follow-up periods of the included studies for Alzheimer's disease and all dementia ranged from three ${ }^{16}$ to seven years ${ }^{15}$ and may be too short to capture overall predictive properties of frailty, leading to smaller risk estimates for Alzheimer's disease. This may be supported by the findings of a previous study showing that frailty based on FI better predicted incident Alzheimer's disease (area under the curve (AUC) $=0.66$ vs. 0.64 ) and all dementia $(\mathrm{AUC}=0.66$ vs. 0.64$)$ over 10 years rather than over 5 years. ${ }^{19}$

Two studies ${ }^{19,20}$ from the Canadian Study of Health and Aging used a deficit accumulation model of frailty, the FI, to examine risks of incident Alzheimer's disease ${ }^{19}$ and all dementia ${ }^{19,20}$. In the first study, ${ }^{19}$ the FI with 19 non-traditional dementia risk factors predicted all dementia (adjusted $\mathrm{OR}=1.02$ per approximately a 0.03 increase in FI, 95\% $\mathrm{CI}=1.01-1.04, \mathrm{p}=0.04)$ independently of traditional risk factors, but did not predict Alzheimer's disease (adjusted $\mathrm{OR}=1.01,95 \% \mathrm{CI}=1.00-1.03, \mathrm{p}=0.06$ ) over 10 years. In the second study, ${ }^{20}$ the FI with up to 42 deficits (both traditional and non-traditional dementia risk factors) predicted incident all dementia (age-adjusted $\mathrm{OR}=1.18,95 \% \mathrm{CI}=1.12-1.25$ in men and age-adjusted $\mathrm{OR}=1.08,95 \% \mathrm{CI}=1.04-1.11$ in women, both per each deficit added). These findings that a higher degree of frailty status described by the FI was a significant risk factor for dementia were in line with our meta-analysis results. Although it is unknown why the FI, especially the one based on non-traditional dementia risk factors, predicted newly developing dementia, the authors hypothesized that an aberrant repair mechanism was involved. ${ }^{20}$

The mechanisms and pathophysiology underlying the increased risks of dementia in frail older people are not clear at present, but both frailty and dementia are complex and heterogeneous entities and are known to share multiple risk factors for their development, including diabetes mellitus, heart attack, hypertension, congestive heart failure, cerebrovascular disease, and chronic inflammation. ${ }^{16,18,31,32}$ It is plausible that frailty and dementia result from the same underlying pathophysiology such as pathological brain changes. ${ }^{16,33,34}$ Recent research from the Rush Memory and Aging Project and Religious Orders Study using longitudinal frailty data over time and brain pathology findings from autopsies showed that Alzheimer's disease pathology was associated with frailty status near death $^{33}$ and that four brain pathology types: macroinfarcts, Alzheimer's disease and Lewy body pathology, and nigral neuronal loss, were significantly associated with a more rapid 
progression of frailty, independent of age, gender, and education. ${ }^{34}$ The brain pathology was only examined at autopsy and, as a matter of course, its baseline data or onset and transition while participants were alive were lacking. ${ }^{34}$ Despite the availability of transitional data on frailty status over time,${ }^{34}$ it could not be inferred based on these findings whether brain pathology contributed to frailty progression or progressive frailty accumulated brain pathology, or whether they co-occurred.

Another possibility is that cognitive impairment might be a part of frailty, rather than being two distinct entities that are common and often co-occurring in old age. Many experts have suggested that cognitive function should be included as one of the frailty criteria, and the International Academy on Nutrition and Aging and the International Association of Gerontology and Geriatrics advocated a new term, "cognitive frailty", as a heterogeneous clinical state characterized by manifesting both physical frailty and cognitive impairment without Alzheimer's disease or other dementia. ${ }^{35}$ It could be speculated from this theory that subclinical cognitive pathophysiology may have started as a part of frailty years before overt dementia developed and frailty seemingly preceded and predicted the development of dementia. Furthermore, a previous study showed that a FI incorporating multidimensional factors, including physical and cognitive components, better predicted adverse outcomes than CHS criteria, which include only physical components. ${ }^{36}$ Another study demonstrated that adding cognitive impairment to CHS criteria improved ability to predict adverse outcomes, including mobility disability, activities of daily living (ADL)/ instrumental activities of daily living (IADL) disability, hospitalization, and death; however, this was not the case for dementia. ${ }^{29}$ Cognitive impairment was shown to be associated with an approximately fivefold increased risk of developing dementia irrespective of frailty status. ${ }^{29}$ Furthermore, there were no significant associations between frailty status and incident dementia, nor was there a dose-response relationship in risk measures according to frailty status in the entire cohort or in subgroups with and without cognitive impairment. ${ }^{29}$ These findings suggested that frailty and cognitive impairment were separate processes. ${ }^{29}$ If frailty and cognitive impairment/dementia were distinct entities, their interactions may have been bidirectional, exacerbating each other in a vicious cycle, as several cross-sectional and longitudinal studies have showed that people with dementia or cognitive impairment were more likely to be frail or become frail..$^{37-41}$

Our meta-regression analysis suggested higher risk of incident Alzheimer's disease according to physical frailty in women than in men. The reason why women had higher risk is not clear at present, but we think one possible explanation for this gender disparity is age-related reduction in sex steroid hormones in both men and women. The deposit of amyloid- $\beta$ peptide in the brain is considered as a pathological hallmark of Alzheimer's disease. ${ }^{42}$ Mitochondria produces more reactive oxygen species when amyloid- $\beta$ peptide is present ${ }^{43}$ and it has been proposed that increased oxidative stress plays an important role in amyloid- $\beta$ peptide-induced neuronal cell apoptosis in Alzheimer's disease. ${ }^{44}$ Frailty has also been shown to be associated with oxidative stress, ${ }^{45,46}$ which may contribute to increased risks of incidence Alzheimer's disease in frail older people. Both estrogen and testosterone are neuroprotective in Alzheimer's disease,${ }^{47}$ especially against oxidative stress. ${ }^{48-50}$ While men experience a gradual decrease in testosterone, women have a rapid loss of estrogen after menopause. As a result, older women may be more susceptible to developing Alzheimer's disease than older men.

This study has multiple strengths. First, our comprehensive and reproducible search strategy was robust using extensive search words and multiple electronic databases. The screening of 
the title, abstract, and full-text and data extraction were conducted by two researchers independently. Between-study variance was further explored using a meta-regression analysis, which showed that the female proportion of the cohorts was a significant modulator. Second, the overall quality of the four studies included in the meta-analysis and metaregression analysis was high; all studies used CHS criteria to define physical frailty and standardized criteria to diagnose dementia, and presented HRs adjusted for important confounders including age, gender, and education. These factors may have contributed to low to moderate heterogeneity across the studies. Lastly, it is of note that the current review and meta-analysis study demonstrated the pooled evidence that physical frailty predicted the incidence of Alzheimer's disease, vascular dementia, and all dementia, given that the findings from previous studies were conflicting and a rigorous meta-analysis had not been conducted.

Our results should be interpreted with caution because of potential limitations. First, the follow-up periods of the studies included in the meta-analyses may be too short to elucidate true associations between frailty and subsequent risks of incident dementia for the aforementioned reason, which could underestimate the risks. Second, since dementia has not frequently been studied in relation to frailty, there were only a limited number of studies available for review. Therefore publication bias and meta-regression analysis were performed only for the four studies on Alzheimer's disease. Third, all studies included in this review were from North America or Europe. Therefore, our findings may not be generalizable to older people in other country and further investigation is needed to explore the association of frailty with dementia among other population. Lastly, all CHS criteria used by the four studies included in the meta-analysis were not original versions but were modified slightly from study to study. These modifications may have potentially affected the findings. ${ }^{51}$

An increasing amount of evidence on frailty has been accumulated in the literature and the theoretical concept of frailty syndrome has gained universal consensus. ${ }^{7,52}$ However, its implementation and translation into clinical settings have not been well achieved. It is not always practical to measure the frailty status of older people during a busy clinic visit because of the lack of time, space, or equipment. For example, in CHS criteria, one needs to measure gait speed and grip strength as well as to identify the lowest $20 \%$ of the cohort that the patient belongs to while one needs to go over a list of as many as 30 or more health deficits in order to construct the FI. Beside CHS and FI, which are the two most popular frailty definitions, some researchers attempted to use methods that were more feasible, such as a tool consisting of five simple questions, ${ }^{53}$ or even walking speed as a single-item screening tool. ${ }^{54}$ These tools can be assessed for validity, which may lead to accelerating the translation of frailty research into clinical use for the risk screening of dementia as well as other adverse health outcomes.

\section{Conclusion}

This systematic review and meta-analysis demonstrated pooled evidence suggesting that frailty was a significant predictor of dementia, including Alzheimer's disease, vascular dementia, and all dementia, among community-dwelling older people. As frailty is a dynamic condition and its status can change over time, interventions against frailty may provide the additional benefit of potentially preventing or delaying dementia.

\section{CONFLICTS OF INTEREST}

None. 


\section{REFERENCES}

1. Alzheimer's Association Report. 2015 Alzheimer's disease facts and figures. Alzheimer's \& dementia : the journal of the Alzheimer's Association 2015;11:332384.

2. Prince M, Bryce R, Albanese E, et al. The global prevalence of dementia: a systematic review and metaanalysis. Alzheimer's \& dementia : the journal of the Alzheimer's Association 2013;9:63-75 e62.

3. World Health Organization and Alzheimer's Disease International. Dementia: a public health priority. 2012; http://www.who.int/mental_health/publications/dementia report 2012/en/. Accessed 26th February 2016.

4. Brayne C, Gao L, Dewey M, Matthews FE. Dementia before death in ageing societies--the promise of prevention and the reality. PLoS medicine 2006;3:e397.

5. Orrell M, Brayne C. Dementia prevention: call to action. Lancet (London, England) 2015;386:1625.

6. Winblad B, Amouyel P, Andrieu S, et al. Defeating Alzheimer's disease and other dementias: a priority for European science and society. The Lancet. Neurology 2016;15:455-532.

7. Clegg A, Young J, Iliffe S, et al. Frailty in elderly people. Lancet (London, England) 2013;381:752-762.

8. Fried LP, Tangen CM, Walston J, et al. Frailty in older adults: evidence for a phenotype. The journals of gerontology. Series A, Biological sciences and medical sciences 2001;56:M146-156.

9. Kojima G. Frailty as a Predictor of Future Falls Among Community-Dwelling Older People: A Systematic Review and Meta-Analysis. Journal of the American Medical Directors Association 2015;16:1027-1033.

10. Kojima G. Frailty as a predictor of hospitalisation among community-dwelling older people: a systematic review and meta-analysis. Journal of epidemiology and community health 2016;

11. Kojima G. Frailty as a predictor of fractures among community-dwelling older people: A systematic review and meta-analysis (Conference abstract). Journal of cachexia, sarcopenia and muscle 2015;6:422.

12. Kojima G, Iliffe S, Jivraj S, Walters K. Association between frailty and quality of life among community-dwelling older people: a systematic review and meta-analysis. Journal of epidemiology and community health 2016;

13. Collard RM, Boter H, Schoevers RA, Oude Voshaar RC. Prevalence of frailty in community-dwelling older persons: a systematic review. Journal of the American Geriatrics Society 2012;60:1487-1492.

14. Kojima G. Prevalence of Frailty in Nursing Homes: A Systematic Review and MetaAnalysis. Journal of the American Medical Directors Association 2015;16:940-945.

15. Avila-Funes JA, Carcaillon L, Helmer C, et al. Is frailty a prodromal stage of vascular dementia? Results from the Three-City Study. Journal of the American Geriatrics Society 2012;60:1708-1712.

16. Buchman AS, Boyle PA, Wilson RS, et al. Frailty is associated with incident Alzheimer's disease and cognitive decline in the elderly. Psychosomatic medicine 2007;69:483-489.

17. Gray SL, Anderson ML, Hubbard RA, et al. Frailty and incident dementia. The journals of gerontology. Series A, Biological sciences and medical sciences 2013;68:1083-1090.

18. Solfrizzi V, Scafato E, Frisardi V, et al. Frailty syndrome and the risk of vascular 
dementia: the Italian Longitudinal Study on Aging. Alzheimer's \& dementia : the journal of the Alzheimer's Association 2013;9:113-122.

19. Song X, Mitnitski A, Rockwood K. Nontraditional risk factors combine to predict Alzheimer disease and dementia. Neurology 2011;77:227-234.

20. Song X, Mitnitski A, Rockwood K. Age-related deficit accumulation and the risk of late-life dementia. Alzheimer's research \& therapy 2014;6:54.

21. Panza F, Solfrizzi V, Frisardi V, et al. Different models of frailty in predementia and dementia syndromes. The journal of nutrition, health \& aging 2011;15:711-719.

22. $\mathrm{Xu} \mathrm{W}$, Tan L, Wang HF, et al. Meta-analysis of modifiable risk factors for Alzheimer's disease. Journal of neurology, neurosurgery, and psychiatry 2015;86:1299-1306.

23. Moher D, Liberati A, Tetzlaff J, Altman DG. Preferred reporting items for systematic reviews and meta-analyses: the PRISMA statement. BMJ (Clinical research ed.) 2009;339:b2535.

24. Stroup DF, Berlin JA, Morton SC, et al. Meta-analysis of observational studies in epidemiology: a proposal for reporting. Meta-analysis Of Observational Studies in Epidemiology (MOOSE) group. Jama 2000;283:2008-2012.

25. Wells GA, Shea D, O'Connell D, et al. The Newcastle-Ottawa Scale (NOS) for assessing the quality of nonrandomised studies in meta-analyses. http://www.ohri.ca/programs/clinical epidemiology/oxford.asp. Accessed 20th August, 2015.

26. Higgins JP, Thompson SG, Deeks JJ, Altman DG. Measuring inconsistency in metaanalyses. BMJ (Clinical research ed.) 2003;327:557-560.

27. Begg CB, Mazumdar M. Operating characteristics of a rank correlation test for publication bias. Biometrics 1994;50:1088-1101.

28. Egger M, Davey Smith G, Schneider M, Minder C. Bias in meta-analysis detected by a simple, graphical test. BMJ (Clinical research ed.) 1997;315:629-634.

29. Avila-Funes JA, Amieva H, Barberger-Gateau $\mathrm{P}$, et al. Cognitive impairment improves the predictive validity of the phenotype of frailty for adverse health outcomes: the three-city study. Journal of the American Geriatrics Society 2009;57:453-461.

30. Jack CR, Jr., Knopman DS, Jagust WJ, et al. Tracking pathophysiological processes in Alzheimer's disease: an updated hypothetical model of dynamic biomarkers. The Lancet. Neurology 2013;12:207-216.

31. Alzheimer's Society. Am I at risk of developing dementia? 2015; https:/www.alzheimers.org.uk/site/scripts/documents info.php?documentID=102. Accessed 24th January 2016.

32. Afilalo J, Karunananthan S, Eisenberg MJ, et al. Role of frailty in patients with cardiovascular disease. The American journal of cardiology 2009;103:1616-1621.

33. Buchman AS, Schneider JA, Leurgans S, Bennett DA. Physical frailty in older persons is associated with Alzheimer disease pathology. Neurology 2008;71:499-504.

34. Buchman AS, Yu L, Wilson RS, et al. Association of brain pathology with the progression of frailty in older adults. Neurology 2013;80:2055-2061.

35. Kelaiditi E, Cesari M, Canevelli M, et al. Cognitive frailty: rational and definition from an (I.A.N.A./I.A.G.G.) international consensus group. The journal of nutrition, health \& aging 2013;17:726-734.

36. Rockwood K, Andrew M, Mitnitski A. A comparison of two approaches to measuring frailty in elderly people. The journals of gerontology. Series A, Biological sciences and medical sciences 2007;62:738-743.

37. Bilotta C, Nicolini P, Case A, et al. Frailty syndrome diagnosed according to the Study of Osteoporotic Fractures (SOF) criteria and adverse health outcomes among 
community-dwelling older outpatients in Italy. A one-year prospective cohort study. Archives of gerontology and geriatrics 2012;54:e23-28.

38. Kulmala J, Nykanen I, Manty M, Hartikainen S. Association between frailty and dementia: a population-based study. Gerontology 2014;60:16-21.

39. Raji MA, Al Snih S, Ostir GV, et al. Cognitive status and future risk of frailty in older Mexican Americans. The journals of gerontology. Series A, Biological sciences and medical sciences 2010;65:1228-1234.

40. Doba N, Tokuda Y, Goldstein NE, et al. A pilot trial to predict frailty syndrome: the Japanese Health Research Volunteer Study. Experimental gerontology 2012;47:638643.

41. Robertson DA, Savva GM, Kenny RA. Frailty and cognitive impairment--a review of the evidence and causal mechanisms. Ageing research reviews 2013;12:840-851.

42. Reitz C, Brayne C, Mayeux R. Epidemiology of Alzheimer disease. Nature reviews. Neurology 2011;7:137-152.

43. Chen X, Stern D, Yan SD. Mitochondrial dysfunction and Alzheimer's disease. Current Alzheimer research 2006;3:515-520.

44. Moreira PI, Smith MA, Zhu X, et al. Oxidative stress and neurodegeneration. Annals of the New York Academy of Sciences 2005;1043:545-552.

45. Mulero J, Zafrilla P, Martinez-Cacha A. Oxidative stress, frailty and cognitive decline. The journal of nutrition, health \& aging 2011;15:756-760.

46. Ershler WB. A gripping reality: oxidative stress, inflammation, and the pathway to frailty. Journal of applied physiology (Bethesda, Md. : 1985) 2007;103:3-5.

47. Pike CJ, Carroll JC, Rosario ER, Barron AM. Protective actions of sex steroid hormones in Alzheimer's disease. Frontiers in neuroendocrinology 2009;30:239-258.

48. Vina J, Lloret A. Why women have more Alzheimer's disease than men: gender and mitochondrial toxicity of amyloid-beta peptide. Journal of Alzheimer's disease : JAD 2010;20 Suppl 2:S527-533.

49. Son SW, Lee JS, Kim HG, et al. Testosterone depletion increases the susceptibility of brain tissue to oxidative damage in a restraint stress mouse model. Journal of neurochemistry 2016;136:106-117.

50. Barron AM, Fuller SJ, Verdile G, Martins RN. Reproductive hormones modulate oxidative stress in Alzheimer's disease. Antioxidants \& redox signaling 2006;8:20472059.

51. Theou O, Cann L, Blodgett J, et al. Modifications to the frailty phenotype criteria: Systematic review of the current literature and investigation of 262 frailty phenotypes in the Survey of Health, Ageing, and Retirement in Europe. Ageing research reviews 2015;21:78-94.

52. Morley JE, Vellas B, van Kan GA, et al. Frailty consensus: a call to action. Journal of the American Medical Directors Association 2013;14:392-397.

53. Morley JE, Malmstrom TK, Miller DK. A simple frailty questionnaire (FRAIL) predicts outcomes in middle aged African Americans. The journal of nutrition, health \& aging 2012;16:601-608.

54. Abellan van Kan G, Rolland Y, Houles M, et al. The assessment of frailty in older adults. Clinics in geriatric medicine 2010;26:275-286. 
Table 1. Summary of prospective studies examining baseline frailty status and subsequent risks of incident dementia among community-dwelling older people.

\begin{tabular}{|c|c|c|c|c|c|c|c|c|c|}
\hline Author/Year & Study (Location) & $\begin{array}{c}\text { Sample } \\
\text { size }\end{array}$ & $\begin{array}{c}\text { Female } \\
(\%)\end{array}$ & $\begin{array}{l}\text { Mean age } \\
\text { (range) }\end{array}$ & $\begin{array}{l}\text { Frailty } \\
\text { criteria }\end{array}$ & diagnostic criteria & $\begin{array}{l}\text { Follow- } \\
\text { up period }\end{array}$ & $\begin{array}{l}\text { Effect } \\
\text { measure }\end{array}$ & NOS \\
\hline \multicolumn{10}{|l|}{ Alzheimer's disease } \\
\hline Gray et al. 2013 & $\begin{array}{l}\text { Adult Changes in } \\
\text { Thought (USA) }\end{array}$ & 2619 & $60.1 \%$ & $\begin{array}{c}76.8 \\
(>=65)\end{array}$ & $\mathrm{mCHS}$ & NINCDS-ADRDA & 6.5 years & aHR & $8 / 9$ \\
\hline Solfrizzi et al. 2013 & $\begin{array}{l}\text { Italian Longitudinal } \\
\text { Study of Aging } \\
\text { (Italy) }\end{array}$ & 2581 & $45.2 \%$ & $\begin{array}{c}73.1 \\
(65-84)\end{array}$ & $\mathrm{mCHS}$ & NINCDS-ADRDA & 3.5 years & aHR & $8 / 9$ \\
\hline $\begin{array}{l}\text { Avila-Funes et al. } \\
2012\end{array}$ & $\begin{array}{l}\text { Three-City Study } \\
\text { (France) }\end{array}$ & 5480 & $61.7 \%$ & $\begin{array}{c}74.0 \\
(65-95)\end{array}$ & $\mathrm{mCHS}$ & DSM-III-R & 7 years & aHR & $8 / 9$ \\
\hline Buchman et al. 2007 & $\begin{array}{l}\text { Rush Memory and } \\
\text { Aging Project } \\
\text { (USA) }\end{array}$ & 823 & $74.6 \%$ & 80.4 & $\mathrm{mCHS}$ & NINCDS-ADRDA & 3 years & aHR & $8 / 9$ \\
\hline Song et al. 2011 & $\begin{array}{l}\text { Canadian Study of } \\
\text { Health and Aging } \\
\text { (Canada) }\end{array}$ & 2599 & - & $\stackrel{-}{(>=65)}$ & FI & NINCDS-ADRDA & 10 years & $\mathrm{aOR}$ & $7 / 9$ \\
\hline \multicolumn{10}{|l|}{ Vascular dementia } \\
\hline Solfrizzi et al. 2013 & $\begin{array}{l}\text { Italian Longitudinal } \\
\text { Study of Aging } \\
\text { (Italy) }\end{array}$ & 2581 & $45.2 \%$ & $\begin{array}{c}73.1 \\
(65-84)\end{array}$ & $\mathrm{mCHS}$ & ICD-10 & 3.5 years & aHR & $8 / 9$ \\
\hline $\begin{array}{l}\text { Avila-Funes et al. } \\
2012\end{array}$ & $\begin{array}{l}\text { Three-City Study } \\
\text { (France) }\end{array}$ & 5480 & $61.7 \%$ & $\begin{array}{c}74.0 \\
(65-95)\end{array}$ & $\mathrm{mCHS}$ & NINCDS-AIREN & 7 years & aHR & $8 / 9$ \\
\hline \multicolumn{10}{|l|}{ All dementia } \\
\hline Gray et al. 2013 & $\begin{array}{l}\text { Adult Changes in } \\
\text { Thought (USA) }\end{array}$ & 2619 & $60.1 \%$ & $\begin{array}{c}76.8 \\
(>=65)\end{array}$ & $\mathrm{mCHS}$ & DSM-IV & 6.5 years & aHR & $8 / 9$ \\
\hline Solfrizzi et al. 2013 & $\begin{array}{l}\text { Italian Longitudinal } \\
\text { Study of Aging } \\
\text { (Italy) }\end{array}$ & 2581 & $45.2 \%$ & $\begin{array}{c}73.1 \\
(65-84)\end{array}$ & $\mathrm{mCHS}$ & DSM-III-R & 3.5 years & aHR & $8 / 9$ \\
\hline $\begin{array}{l}\text { Avila-Funes et al. } \\
2012\end{array}$ & $\begin{array}{l}\text { Three-City Study } \\
\text { (France) }\end{array}$ & 5480 & $61.7 \%$ & $\begin{array}{l}74.0 \\
(65-95)\end{array}$ & $\mathrm{mCHS}$ & DSM-III-R & 7 years & aHR & $8 / 9$ \\
\hline $\begin{array}{l}\text { Avila-Funes et al. } \\
2009\end{array}$ & $\begin{array}{l}\text { Three-City Study } \\
\text { (France) }\end{array}$ & 4827 & $61.2 \%$ & $\begin{array}{c}74.1 \\
(65-95)\end{array}$ & $\mathrm{mCHS}$ & DSM-IV & 4 years & aHR & $8 / 9$ \\
\hline Song et al. 2014 & $\begin{array}{l}\text { Canadian Study of } \\
\text { Health and Aging } \\
\text { (Canada) }\end{array}$ & 2902 & $0 \%$ & $(>=65)$ & FI & DSM-III-R & 10 years & $\mathrm{aOR}$ & $6 / 9$ \\
\hline Song et al. 2014 & $\begin{array}{l}\text { Canadian Study of } \\
\text { Health and Aging } \\
\text { (Canada) }\end{array}$ & 4337 & $100 \%$ & $(>-\bar{c})$ & FI & DSM-III-R & 10 years & $\mathrm{aOR}$ & $6 / 9$ \\
\hline Song et al. 2011 & $\begin{array}{l}\text { Canadian Study of } \\
\text { Health and Aging } \\
\text { (Canada) }\end{array}$ & 2790 & - & $\begin{array}{c}- \\
(>=65)\end{array}$ & FI & DSM-III-R & 10 years & $\mathrm{aOR}$ & $7 / 9$ \\
\hline \multicolumn{10}{|c|}{ Other dementia category (not included in meta-analysis) } \\
\hline $\begin{array}{l}\text { Gray et al. } 2013 \\
\text { (Non-AD dementia) }\end{array}$ & $\begin{array}{l}\text { Adult Changes in } \\
\text { Thought (USA) }\end{array}$ & 2619 & $60.1 \%$ & $\begin{array}{c}76.8 \\
(>=65)\end{array}$ & $\mathrm{mCHS}$ & DSM-IV & 6.5 years & aHR & $8 / 9$ \\
\hline $\begin{array}{l}\text { Solfrizzi et al. } 2013 \\
\text { ( Non-AD non-VaD } \\
\text { dementia) }\end{array}$ & $\begin{array}{l}\text { Italian Longitudinal } \\
\text { Study of Aging } \\
\text { (Italy) }\end{array}$ & 2581 & $45.2 \%$ & $\begin{array}{c}73.1 \\
(65-84)\end{array}$ & $\mathrm{mCHS}$ & ICD-10 & 3.5 years & aHR & $8 / 9$ \\
\hline
\end{tabular}

AD: Alzhemer's disease

aOR: Adjusted odds ratio

aHR: Adjusted hazard ratio

DSM: Diagnostic and Statistical Manual of Mental Disorders

FI: Frailty Index

ICD: International Statistical Classification of Diseases and Related Health Problems

mCHS: Modified Cardiovascular Health Study frailty index (Fried's phenotype)

NINCDS-AIREN: National Institute of Neurological and Communicative Disorders and 
Stroke-Association Internationale pour la Recherche en l'Enseignement en Neurosciences NINCDS-ADRDA: National Institute of Neurological and Communicative Disorders and Stroke and Alzheimer's Disease and Related Disorders Association

VaD: Vascular dementia 
Figure 1. Systematic review flow chart of study selection process

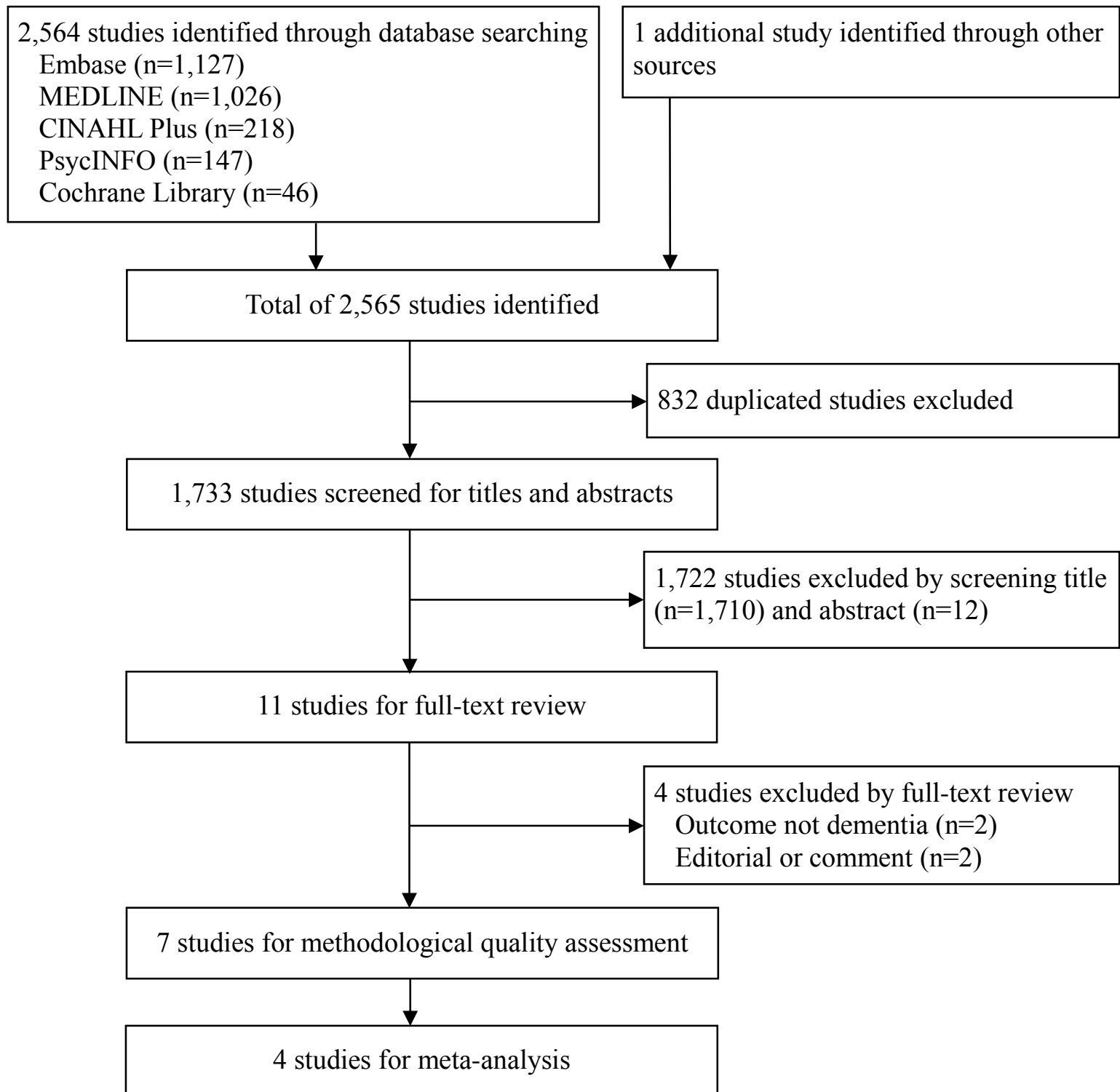


Figure 2. Forest plots of incident Alzheimer's disease, vascular dementia, and all dementia risk according to frailty and prefrailty.

A. Alzheimer's disease

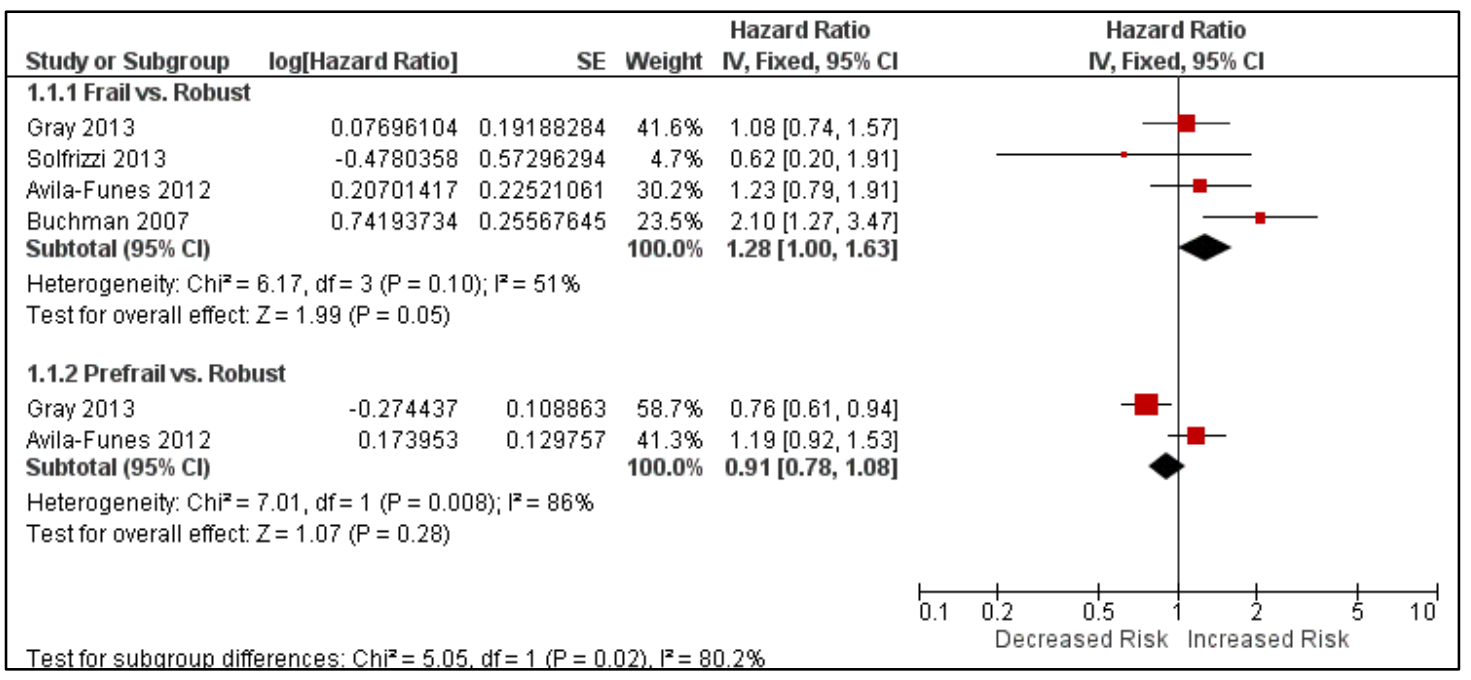

B Vascular dementia

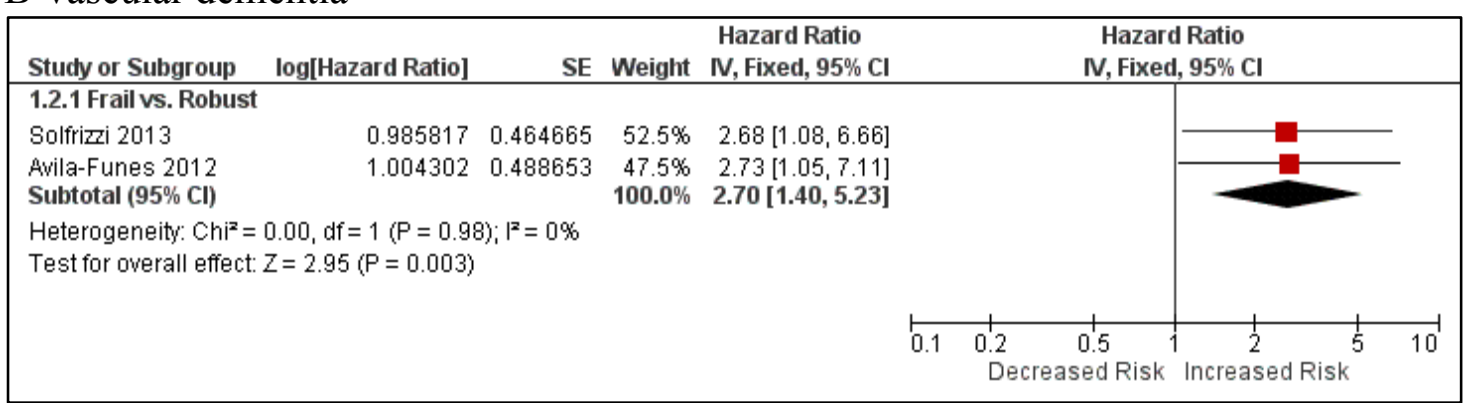

C All dementia

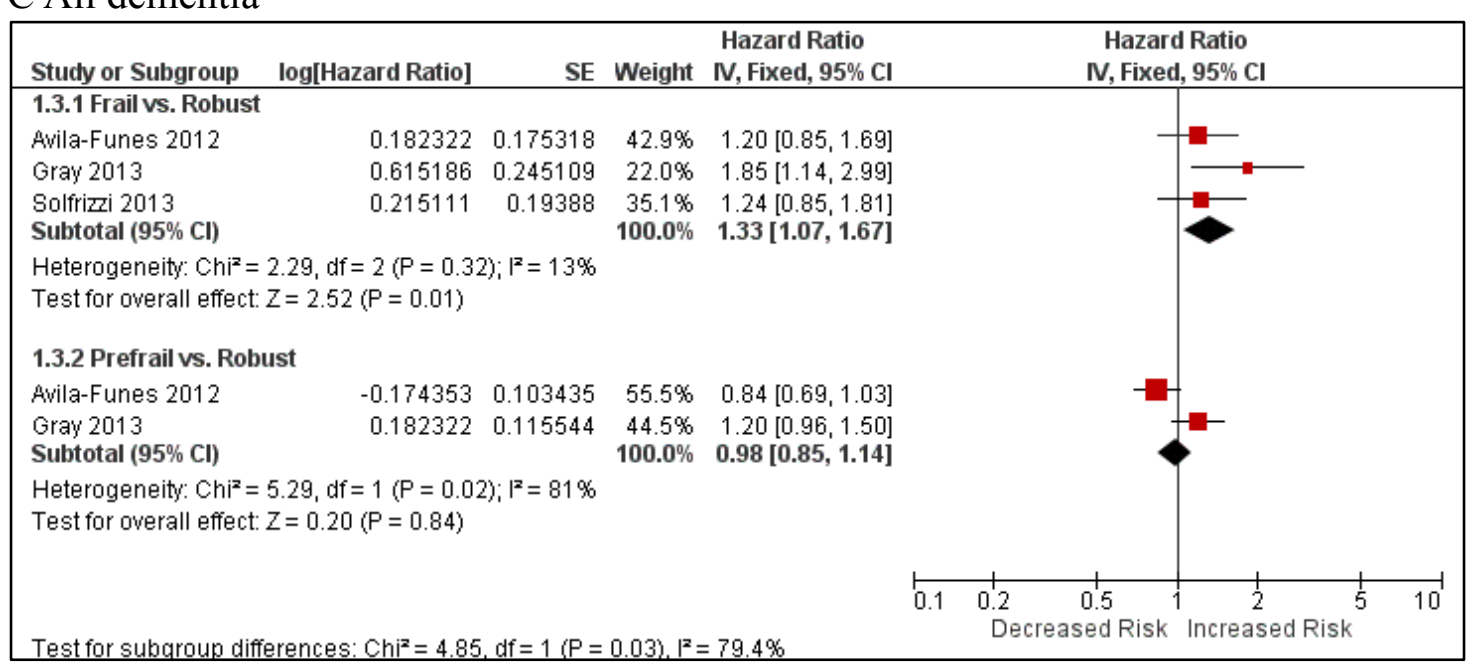


Figure 3. Bubble plot with fitted meta-regression line (black) along with $95 \%$ confidence interval lines (gray) for the association between female proportion and risk of incident Alzheimer's disease by frailty.

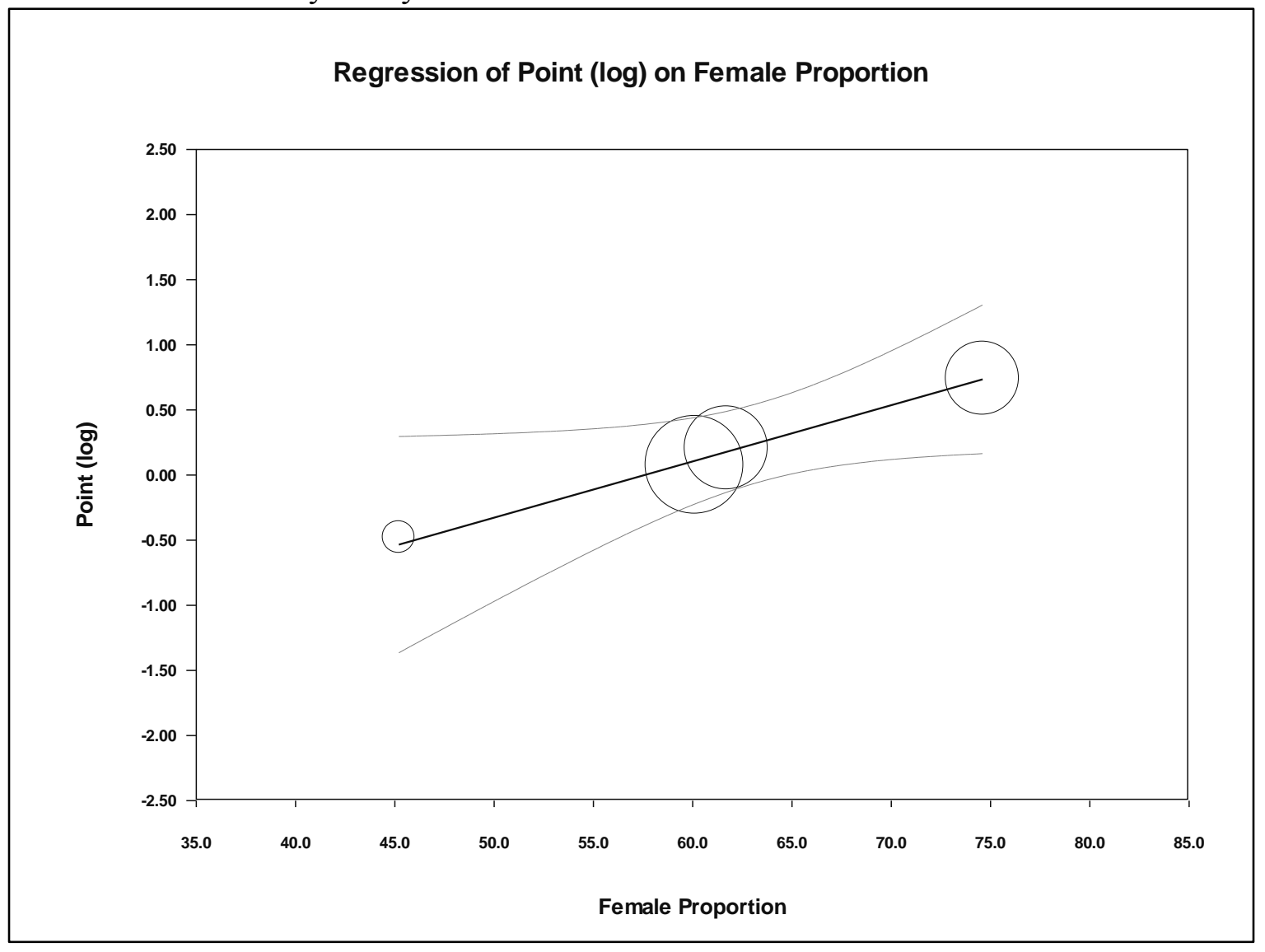

